\title{
Saint-Petersburg landscape scenarios and green architecture in the strategy of urban development
}

\author{
Andrey Vaytens ${ }^{1}$, and Yulia Yankovskaya ${ }^{1, *}$ \\ ${ }^{1}$ Saint Petersburg State University of Architecture and Civil Engineering, Department of Urban \\ Planning, Vtoraya Krasnoarmeyskaya str. 4, Saint Petersburg, 190005, Russia
}

\begin{abstract}
The evolution of architectural and urban planning practice is only possible through an essential understanding of the basic trends of development for architecture in the contemporary world and their historical backgrounds. One of the most important trends is «green architecture» and «perception the city as landscape». The study looks at the specifics of landscape scenarios development in Sankt-Petersburg and prospects for the inclusion of green architecture into the structure of City Plans and General Plans. Landscape scenarios and elements of green architecture are considered in the context of their historical development, structural features, compositional and design techniques. The article examines in detail the historical stages of the introduction of elements of green architecture in landscape scenarios in the City Plans and General Plans of Sankt-Petersburg-Leningrad in XX century.
\end{abstract}

\section{Introduction}

The historical basis of one of the theoretical principle of Landscape Urbanism: "...perception the city as landscape, the common visual and mental image" could be traced in the stages of development of the European cities, also the Russian ones. Thus, the landscape scenarios are not the inventions of to-day s practice, but could be traced in the City plans of many European cities, also of Sankt-Petersburg.

In the urban development of Sankt-Petersburg, the former capital of Russian Empire, one can trace the definite landscape scenarios in the City plans only since the beginning of the XX century. Before this time, the city landscapes (mainly Empire gardens) were located in the city center and not united in one system $[1,2]$.

After October Revolution of 1917 the Soviet Government regarded the city landscapes as the important means of ideology. The architects of the Soviet Petrograd, later (since 1924) Leningrad developed the traditions of landscape architecture of this city. The results of these works - the landscape scenarios were presented in the General Plans of Leningrad of 1935, 1948, 1966 and 1987 [4, 5].

Some fragments of these scenarios were realised in different periods of the city development.

\footnotetext{
*Corresponding author: jul3203226@gmail.com
} 
The evolution of the architectural and urban planning practice are only possible through an essential understanding of the basic trends that set the direction of development for architecture in contemporary world.

Some of the most important trends that modern architecture is facing today is sustainable methods of urban planning and construction that use green architecture and potential of local landscapes and climate. Of course, green architecture in the broadest sense of this complex phenomenon, is the most revealing step on the way towards sustainable development of city, use of its natural and landscape potential.

In this article we examines the historical stages of the introduction of elements of green architecture in landscape scenarios of spatial organization on the example of evolution of the City Plans and General Plans of Sankt-Petersburg-Leningrad in XX century and contemporary trends of development of the city Sankt-Petersburg.

We limit ourselves to urban planning and urban design, architecture and urban environment problems.

Our viewpoint on green architecture will be presented in three sections: historical stages of development landscape scenarios, general scientific concepts and architectural design.

\section{Materials and methods}

The methodological basis of this study is the use of historical, typological, graphicanalytical and compositional approaches.

From the point of view of the analysis of architectural approaches of planning and design, we rely on scenario and structural methods, as well as the method of comparative analysis of town planning documents of different time periods.

In this article, we would like to give our own interpretation of the theoretical concepts of green architecture. Theoretical interpretations include three units: architecture of barriers and stimulus; poetry of boundariness; and variable multilayered environment.

Architecture of Barriers and Stimulus. This position is fundamental and it is based on two theses. Thesis one - the phenomenological direction is oriented to establishing the fundamentals of spatial form organization from the standpoint of an individual with his corporeity. Thesis two - the system «barrier - stimulus» introducing the standpoint of a subject with biological stereotypes underlying it. «Barrier» limits movement and defines space for possible action; «stimulus» coordinates and stimulates possible movements of the individual [7].

Poetry of Boundariness. Poetry of Boundariness. Architectural form generation is revealed through the poetics of the barrier's contours, the art of creation of boundariness. The character of the barrier may vary over a broad range: from a multilayered barrier to a nested system of spatial volumes (both principal and buffer ones) and relationships between them; in the degree of penetrability and optical characteristics of the material barrier; in the visual permeability and stability / instability of the optical barrier; the degree of inclusion of natural components as barriers (plants, water, etc.) [7, 8]

Variable Multilayered Environment. The evolution of the contemporary architecture demonstrated the crossing from traditional concepts of static volumes to variable multilayered structures and enclosed systems as a basis for the concept of sustainable development of city [7]. The newest architectural objects are becoming multi-environment objects including: interior spaces, buffer spaces separating to a varying degree from exterior effects, open exterior environments with natural components.

\section{Results}




\subsection{Historical stages of introduction of landscape scenarios City Plans and General Plans of Sankt-Petersburg-Leningrad in XX- XXI century}

Stage 1. In 1910 the architects Leon Benois (1856- 1928), Marian Peretjatkovich (1872 1916) together with engineer Fedor Enakiew (1852 - 1915) worked out the "Plan of transformation of Sankt Petersburg" (Figure 1).

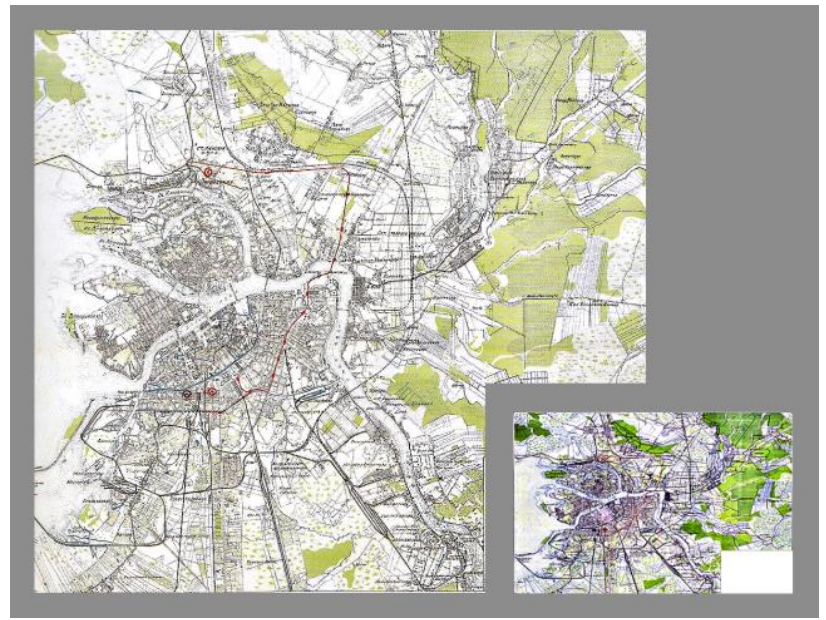

Fig. 1. The city plan of transformation of Saint Petersburg (city plan 1912, scheme 1910).

Though this Plan was the urban planning initiative of these architects and was confirmed on the city level, it was very important event in the development of the Russian capital. In this plan the orientations of the further development of the city towards the North and the East were presented. It were the high level, green territories. For the first time, the metro system, connecting all existed railway stations, was proposed in this plan $[1,3]$.

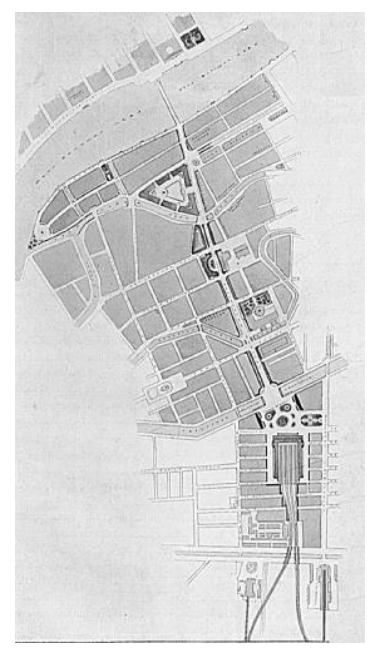

Fig. 2. The prospect of Nicolas II the boulevard over Obwodny canal.

In this plan the local landscape scenario was presented. Its idea was to form over Krukow Canal, the new boulevard, connecting the square of the new City railway station with the Theater Square and, further, through the Blagoweshensky bridge, with Vassiliewsky Island. (Figure 2, 3) [6]. 


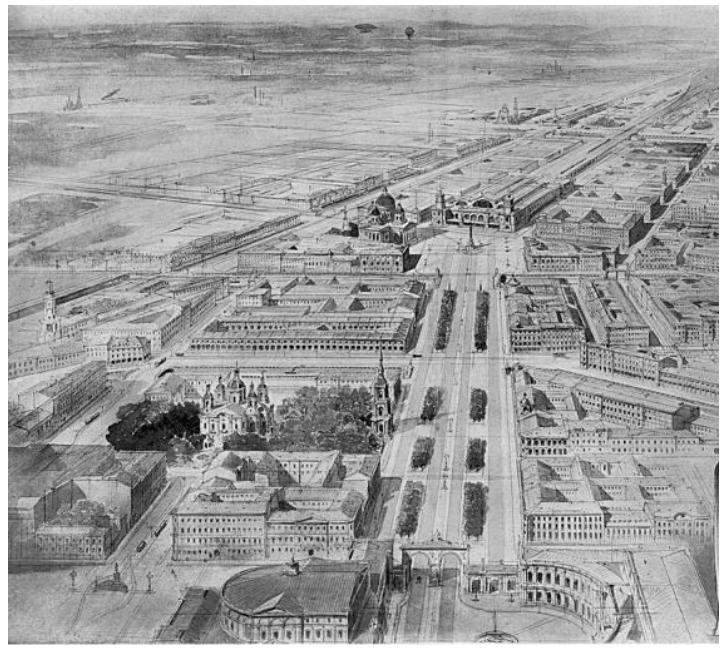

Fig. 3. The prospect of Nicolas II (perspective).

The economical substantiation of this project was made by one of the authors - Fedor Enakiew himself. The World War I prevented from realisation of this landscape idea.

The next landscape scenario, already of the Soviet times and city scape, was presented in the General Plan of Leningrad, which was worked out by famous Russian architect and city planner Lev Iljin (1880-1942)[1] in 1935 (Figure 4).

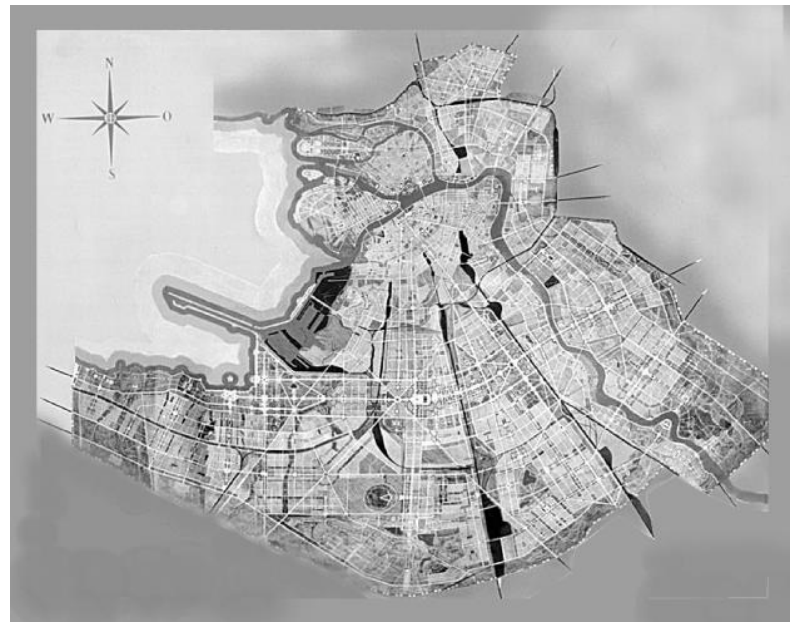

Fig. 4. General Plan of Leningrad (1935).

The idea of this scenario was the forming of the system of parks on the Elagine, Krestowsky and Kamenny islands, in the northern part of the city.[ 1, p.180] On the Krestowsky Island the site of the City stadium for 70000 spectators was defined (Figure 5). 


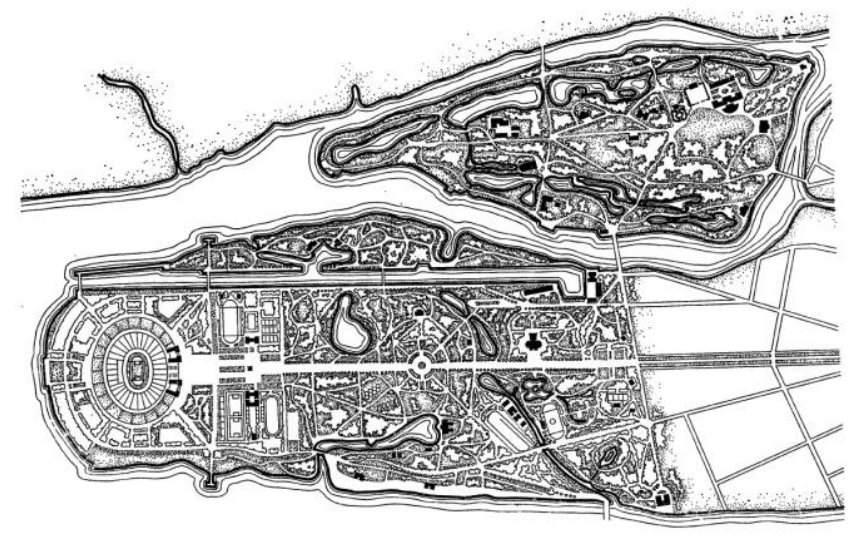

Fig. 5. City park (Krestowsky island) and the location of the City stadium.

Also according to this scenario, the north-western part of Basil Island, orientated to the Gulf of Finland, was planned as the city recreation territory with the small parks and sport facilities. Besides, this landscape scenario envisaged the creation of the uninterrupted system of parks along the western, southern and south-eastern city borders. Also, the system of the landscape spaces in the south-western part of the city, located southwards of the Cargo port and orientated to the Gulf of Finland, was proposed[ 1,p.98]. The realisation of this landscape scenario could provide the population of the central part of Leningrad with recreation possibilities. The Second World War prevented from the realisation of the southern and western parts of this scenario.

Stage 2. The post war landscape scenario of Leningrad was a part of the General Plan of reconstruction and development of the city, confirmed in 1948[3] (Figure 6). This plan and this scenario were worked out by the City architect Nicolas Baranow (1909-1989).

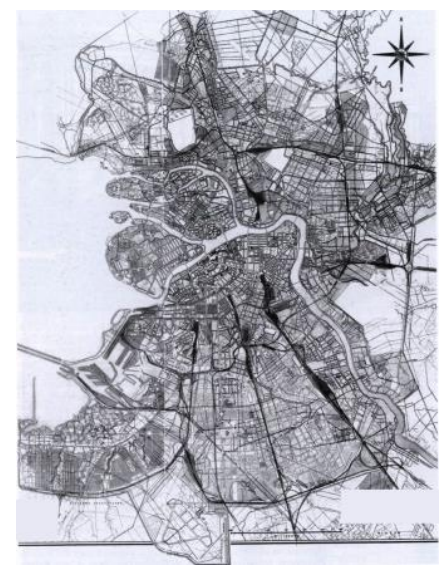

Fig. 6. General Plan of reconstruction of Leningrad (1948).

In 1948 the post-war General Plan of reconstruction and development of Leningrad was finished.The landscape scenario, which was the part of this Plan, stipulated the formation of the City Park - the continuous system of the green spaces of $6 \mathrm{~km}$ long - along the Malaja Neva - from Peter and Paul fortress up to the end of Petrowsky Island (Figure 7). This City Park could be the part of the common landscape with the developed gteen spaces of Krestowsky and Elagine Islands.[2, p.12]. 


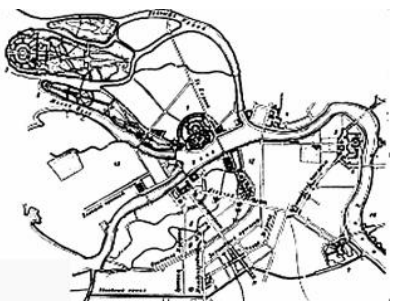

Fig. 7. The City Park in the scheme of reconstruction of Leningrad (1948).

Sorry to say, this Park, being so necessary for the city center, wasn't realised. During the 1950-ies - 1960-ies these territories were developed with the industries and, partly, with the dwellings. The post war landscape scenario had also the ideological aim - to commemorate the victory of USSR in the World War II. It was planned to create of the memorial Park of Victory in the middle of the city avenue - Moscow prospect (Figure 8).
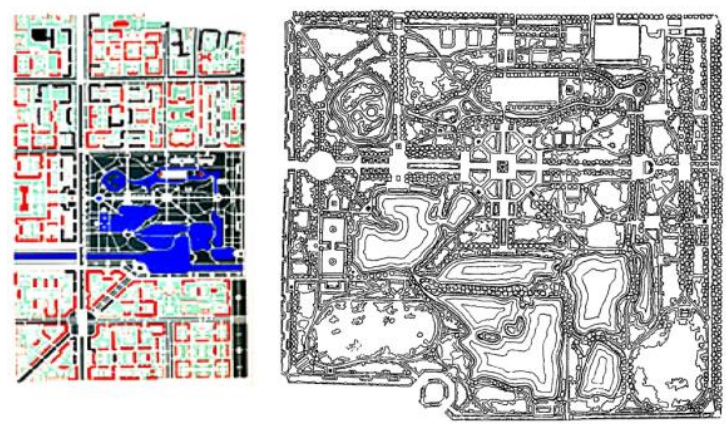

Fig. 8. The Park of Victory (1945 - the 1950-ies).

This Park was found in 1945 and was later developed in connection with the construction of the Sport arena in its eastern part. In the General Plan of Leningrad, which was confirmed in 1966 for the period of 20 years, the city landscape scenario was also proposed [5,pp $72-78]$ (Figure 9). It was differ from the previous ones.
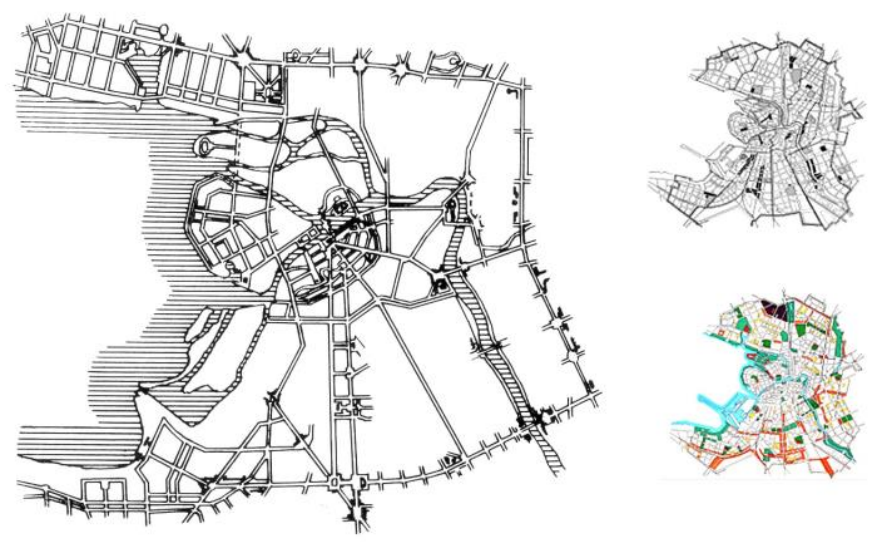

Fig. 9. Design scheme of the master plan in 1966. Planning structure and the centers. The landscape scheme.

In the beginning of the 1960-ies the green spaces were located in Leningrad very unevenly. The landscape scenario of General Plan of 1966 envisaged the even distribution 
of the green spaces of different scales in all the city territories. In this scenario was proposed the following hierarchy of the green spaces: the city parks and woodparks (the allcity level) - the parks of the planning regions of the city with the sport facilities - dwellig block landscapes (the level of several dwelling groups) - the defensive green spaces along the the traffic lines [5,p.113].

Realisation of this scenario could enlarge the total quantity of the city green spaces more than twice - from $18 \mathrm{~km} 2$ up to $38 \mathrm{~km} 2$ [5,p.115]. In the following 20 years this scenario was realised only partly - because of the economical reasons and the necessity of the construction on the free territories [6].

Stage 3. In the next urban city plans - The General Plan development of Leningrad and Leningrad region (1987-2005) [5]( Figure 10) and The General Plan of development of Sankt Petersburg 2005 - 2025[6] (Figure 11).

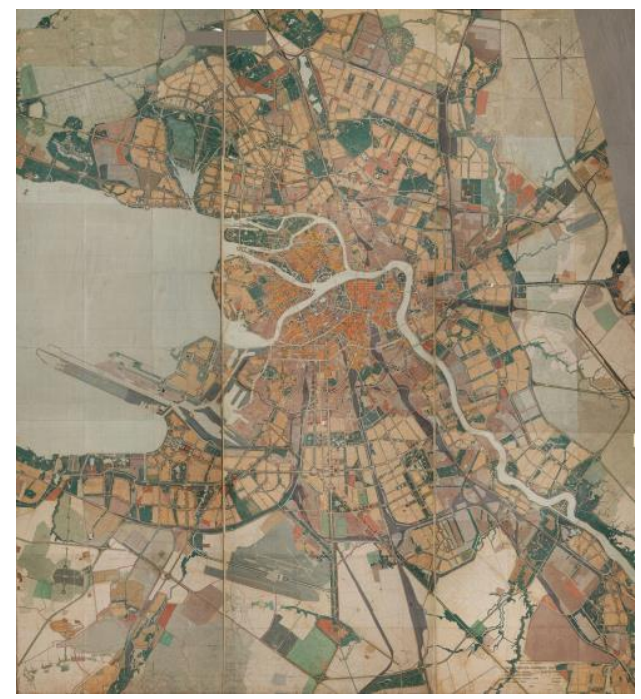

Fig.10. The General Plan of development and Leningrad region (oblast) 1987 - 2005).

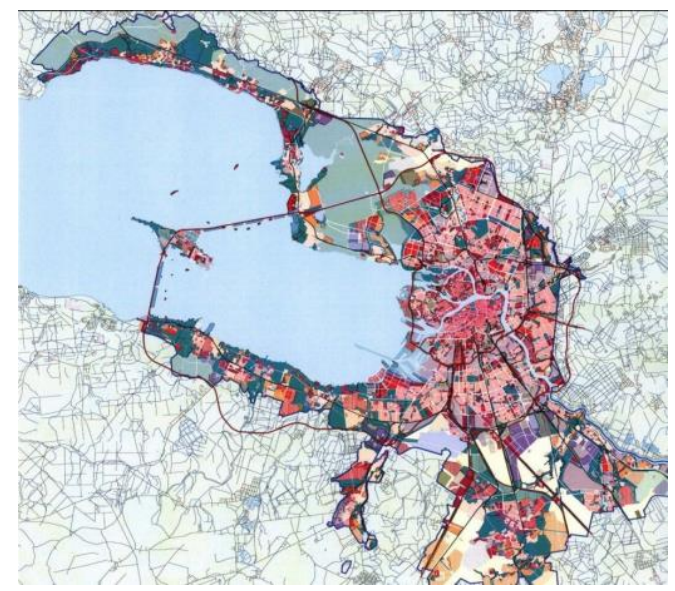

Fig. 11. The General Plan of Sankt-Petersburg (2005 - 2025).

There were no certain, defined landscape scenarios of the city scale. In these city Plans it was proposed to preserve and reconstruct the green spaces of different scales (parks, city historical gardens, boulevards), which already existed. 
These proposals were fulfilled only partly. Because of the dense commercial development in the historical center of Sankt Petersburg in the 1990-ies - 2000-ies many small gardens, typical for the central part of the city - disappeared. No new green spaces of the city scale were planned both in the city center and in new dwelling regions.

The problem of the formation of the green framework of the city of St. Petersburg and the inclusion of landscape scenarios in the strategy of spatial development of the city remains actual.

\subsection{Green architecture as a way to solve the landscape problems of urban planning}

In this section, we will turn our attention to the complex formation of the architectural environment of the city by introducing green architecture techniques in the design of landscape and socially significant objects $[7,11,16]$.

The creative potential that is available in to-day Russian architecture can be fully discovered only in the conceptual projects experience such as: competitive projects and experimental projects. We want to show some interesting projects of both young and experienced Russian architects who have accepted ideas of green architecture. The projects will be demonstrated under three headings: nature-friendly; nature-dissolving; naturesimilar; and nature-inclusive.

«Nature-friendly» project. Great opportunities to create multilayered barriers and adaptive and multi-environmental objects are offered by the treatment of public infrastructure in the form of new stage of the Alexandrinsky Theater in St. Petersburg (Figure 12) [14]. The main idea of this Complex is the creation of a nature-friendly environment for citizens. This project combine the mottos «nature around, nature inside, nature on» and «variable multilayered environment» [7].

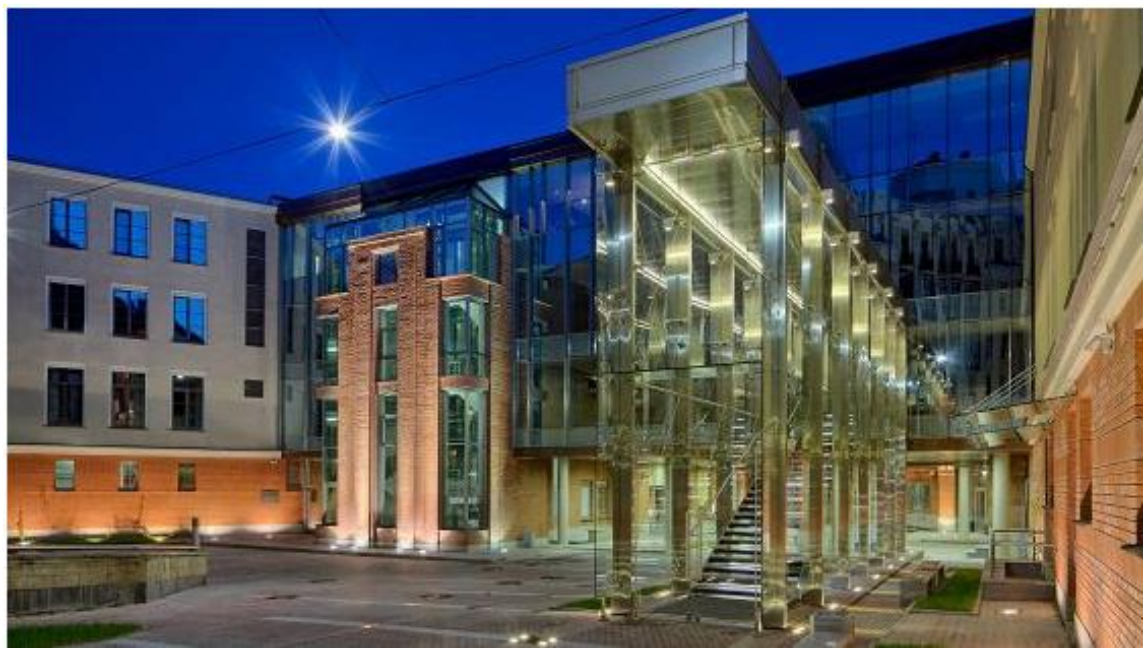

Fig. 12. The new stage of the Alexandrinsky Theater was built according to the project of St. Petersburg architect Yuri Zemtsov in 2013.

«Nature-dissolving» experimental project. Development of this idea can be seen in the project Water Park in Ekaterinburg (Figure 13). The emphasis in this project is made on disclosure of the ideas: «poetry of boundariness» and «architecture of natural barriers». The concept of this complex is directed at including surrounding natural elements and forming an eco-oriented nature-friendly humanistic and harmonious environment. The use of the 
relief for the landscape of St. Petersburg is relevant for north-west territories developing along the direction to Kurortnoy district $[8,12,14]$.

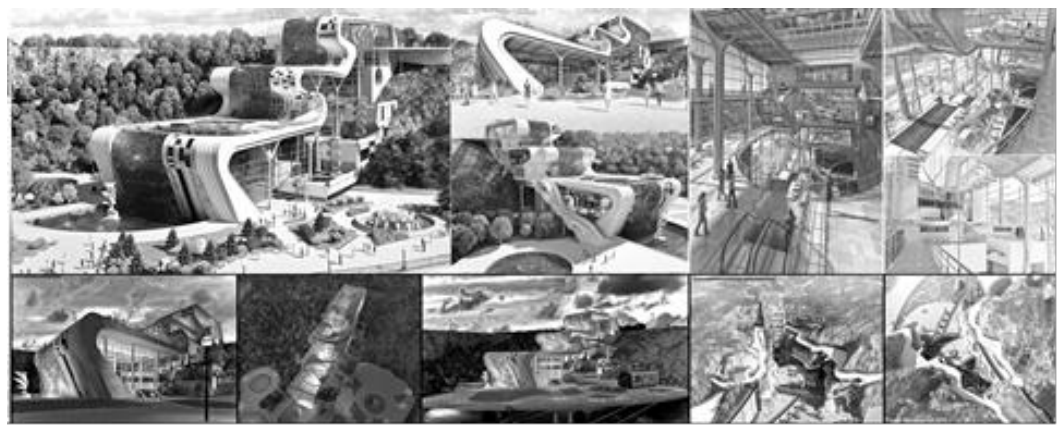

Fig. 13. The experimental project «Water Park» by P.Korepin, A. Merenkov, N. Doronina.

«Nature-inclusive» experimental project is devoted to Residential and Multifunctional City Complexes. The main ideas of nature-inclusive complexes are compensation of the adverse effects of the industrial urban environment and introduction of nature components into architectural objects. The roof gardens and green walls are located on the architectural volumes; green atriums and winter gardens are integrated into the buildings. The emphasis in this project is made on disclosure of the ideas: "architecture of barriers and stimulus" and «variable multilayered environment» [9, 10, 13]. (Figure 14).

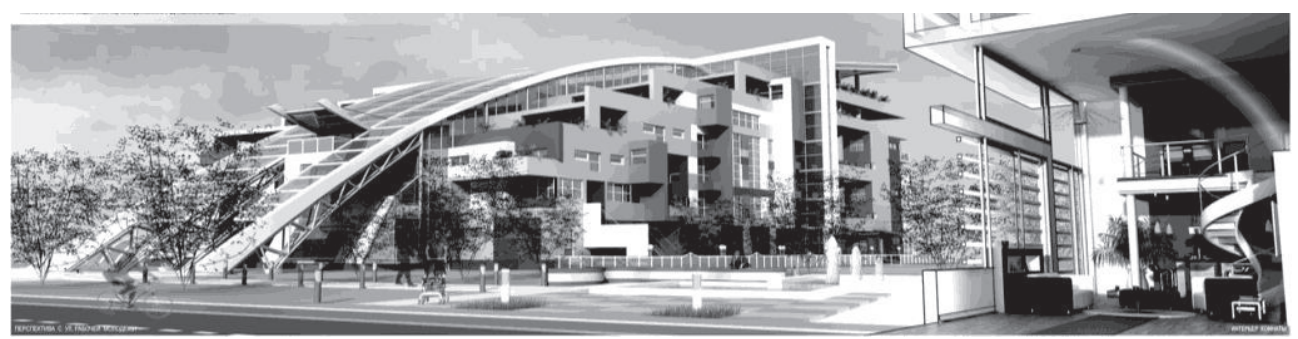

Fig. 14. The experimental project «Residential Building» by A.Chirkov, A. Merenkov.

The theoretical interpretation of the "green architecture" becoming a way of solving design objectives as well as a metaphor for defining artistic appearance of the architectural object. Theoretical concepts have many interpretations in project work, but they are meant to stimulate design experimentation and discovery of new approaches to architectural form generation and implementation of the ideas of «green architecture» $[10,12,16]$.

\section{Discussion}

What should be done to improve this situation in Sankt Petersburg? In present, for the creation of the steady ecologically and aesthetically attractive environment of the Russian cities and also Sankt-Petersburg, it s necessary to apply the ideas of the Landscape Urbanism for the reconstruction of the former industrial and traffic city territories and embankments. Since the majority of the city territories of Sankt-Petersburg are densely developed, also with the new commercial dwelling complexes, the territories of the former industries and traffic could be the suitable places for the future landscape scenarios of this city. The introduction of ideas and techniques of green architecture in the formation of the urban environment and socially significant buildings will solve part of the problems of urban planning in terms of introducing the natural component. 


\section{Conclusions}

1. The article poses the problem of sustainable development of the city of St. Petersburg, the implementation of its strategic plans for the development of landscape scenarios and elements of «green architecture"

2. The main stages of the introduction of landscape scenarios into City Plans and General Plans of Sankt-Petersburg-Leningrad existed in XX- XXI century. This experience could be used in to-days improvement of existing complicated ecological situation.

3. Tendencies of introduction of a natural element by means of receptions of green building in the conditions of St.-Petersburg.

\section{References}

1. E.P. Busireva, Lev Ilyine (GMI SPb, Spb, 2008)

2. Architecture of Leningrad 3, 10 (1945)

3. Catalogue of the exhibition "300 years of the urban planning and design activities in Saint Petersburg 1706 - 2006” (SPb, 2006)

4. Catalogue of the exhibition "100 anniversary of the birthday of N.Baranow" (SPb, 2009)

5. V. Kamensky, The General Plan of city development (Lenisdat, Leningrad, 1972)

6. Y. Yankovskaya, Architectual-environmental object: Image and Morfology (Architecton, Yekaterinburg, 2012)

7. A. Merenkov, Y. Yankovskaya, Structure of the Civil Building (Architecton, Yekaterinburg, 2012)

8. A. Radford, S.B. Moroc, A. Strivastava, The Elements of Modern Architecture. Understanding Contemporary Buildings (Thames \& Hadson, 2014)

9. C.G. Crysler, St. Cairns, H. Heynen, The SAGE Handbook of Architectural Theory (SAGE Publication Ltd, 2012)

10. A. Yudina, Garden City. Supergreen Buildings, Urban Skyscapes and the New Planted Space (Thames \& Hadson, 2017)

11. H. Plammer, The Experience of Architecture (Thames \& Hadson, 2016)

12. A. Betsky, Architecture Matters (Thames \& Hadson, 2017)

13. https://kudago.com/spb/list/sovremennaya-arhitektura-v/

14. R. Stevens, Ph. Baeck, M. Reijntjes, Roof Gardens (Tectum Publishers, Barcelona 2005)

15. K. Yang, Eco Skyscrapers (Images Publishing, Australia, 2007) 